\title{
Effect of different shading intensities on growth and yield of cherry tomato
}

\author{
M. B. Argade ${ }^{1}$, J. H. Kadam ${ }^{1}$, V. K. Garande ${ }^{2}$, D. R. Patgaonkar ${ }^{2}$, V. S. Patil ${ }^{2}$ and P. N. \\ Sonawane $^{2}$ \\ ${ }^{1}$ Post Graduate Institute of Post-Harvest Management, Killa- Roha, Dist. Raigad - 402116 (MS) , INDIA \\ ${ }^{2}$ College of Agriculture, Kolhapur - 416004 (MS), INDIA \\ *Corresponding author. E-mail: jhkadammpkv@gmail.com
}

Received: October 9, 2017; Revised received: October 28, 2017; Accepted: February 8, 2018

\begin{abstract}
Cherry tomato (Solanum lycopersicon var cerasiforme) is small size fruits, with a bright red colour resembling to cherry and becoming popular in the retail chains which are marketed at a premium price. The field experiment was conducted to study the effect of different (35, 50 and 75 per cent) shading intensities on growth and yield $\left(\mathrm{qha}^{-1}\right)$ of cherry tomato. Significantly maximum yield was recorded in 35 per cent shading intensity and genotype Kalash Seeds Product (KSP)-113 (579.44 and $503.88 \mathrm{q} \mathrm{ha}^{-1}$, respectively). Among the different shading intensities and genotypes, maximum plant height was observed in 75 per cent shading intensity and genotype KSP -113 at 30 days interval $(74.70$ and $60.95 \mathrm{~cm}$, respectively). The minimum days to $50 \%$ flowering of cherry tomato were observed in cherry tomatoes grown under 35 per cent shading intensity (45.00 days) as compared to other shading intensities while minimum days to $50 \%$ flowering were observed in genotype KSP-113 (44.00 days). The maximum length of the cluster $(9.58 \mathrm{~cm})$, the weight of cluster $(27.67 \mathrm{~g})$, number of fruits per cluster $(9.42)$ and number of pickings (11.67) were observed in 35 per cent shading intensities and in genotype KSP-113. The cultivation of KSP-113 genotype under 35 per cent shading intensity was found to be most sustainable for improving growth and yield of cherry tomato during the summer season.
\end{abstract}

Keywords: Cherry tomato, Shade net, Shading intensities, Growth, Yield

\section{INTRODUCTION}

Cherry tomato (Solanum lycopersicon var cerasiforme) is a small fruited variety of tomato and generally considered to be similar but not identical to the wild precursor of the domestic tomato (Lycopersicon esculantum). They are characterized by their small size fruits, with a bright red colour resembling cherry and having an excellent taste. Cherry tomatoes are becoming popular in the retail chains and marketed at a premium price compared to regular tomatoes. It is considered as an exotic vegetable, bringing new taste and appearance to dishes. Open field cultivation of vegetables is often damaged by unfavorable weather conditions especially during sensitive stages of growth and development. Cherry tomato is a very sensitive vegetable, and even a slight variation in any of the weather parameters would lead to significant changes in growth physiology of the crop resulting in considerable yield loss. It is a relative warm season crop. Plants grow well at the temperature range of $19^{\circ} \mathrm{C}$ to $30^{\circ} \mathrm{C}$. It also requires plenty of sunshine, but low humidity, continuous rain in the hot weather will increase disease problems such as bacterial wilt, blight, rot and Fruit cracking. In order to produce high quality fruits with enhanced productivity, cherry tomato could be grown under shade net houses. The shade net house protects the crop from adverse climatic conditions. There are several varieties / hybrids available in cherry tomato (Mantur et al., 2014). However, there are very few studies on evaluation of varieties of cherry tomato under different shading intensities have been made. Hence, the aim of present study is to identify suitable variety and shading intensity for shade net house cultivation of cherry tomato.

The influence of micro environment on the growth of cherry tomato would be much helpful in tapping the potential yield under protected cultivation. Identification of high yielding small fruited $F_{1}$ hybrids, suitable for growing in the greenhouse and open field conditions will help for the successful commercial cultivation of cherry tomato. Genotypes show wide fluctuations in their yielding ability when grown in different environments. Study of stability parameters is useful to identify the stable cultivars. Therefore, the investigation on the performance of cherry tomato genotypes under shade net house with different shading intensities was carried out.

\section{MATERIALS AND METHODS}

The field experiment was conducted to study the effect of different shading intensities on growth and yield of 
cherry tomato at Horticulture Section, College of Agriculture, Kolhapur (Maharashtra) during summer 2015. The four genotypes of cherry tomatoes viz., EC128021, EC-539, KSP-113 and EC-123021 were cultivated in three shade net houses having 35,50 and 75 per cent shading intensities and in open field conditions. The genotypes EC-128021, EC-539 and EC123021 were collected from Tomato Improvement Project, Mahatma Phule Krishi Vidyapeeth, Rahuri and genotype KSP-113 was collected from Kalash Seeds Pvt. Ltd., Jalna, Maharashtra. The experiment was laid out in Factorial Completely Randomized Design. The two lateral drip lines were arranged on each bed along the crop row and drippers were placed to each plant at the spacing of $60 \mathrm{~cm}$. The shade net was provided with the foggers to protect the crop from excessive heat and to control the humidity. The mean optimum relative humidity required during cultivation of cherry tomato is ranged from 78 to 93.2 per cent at morning and 22 to 62.5 per cent at evening. The healthy seedlings were transplanted in March 2015 at the spacing of $60 \times 60$ $\mathrm{cm}$ on the raised beds under shade net. Plants were irrigated on every alternate day through drip irrigation system laid on the bed. Water soluble fertilizers were applied through fertilizer tank initially $1 \frac{1}{2}$ month $\mathrm{N}$ : P: K $(1: 2: 0.5)$ and onwards N: P: K $(2: 1: 3)$ on alternate day. The micronutrients were applied through the foliar spray.

The 5 plants were randomly selected and tagged from each treatment from all the 3 replications to record the periodical observations during experimentation. The height of plant at 30 days interval after transplanting was measured from the ground level to the tip of the plant. A number of days were calculated from transplanting of the seedling to the day on which the 50 per cent flowering of plants, out of total plants observed. The number of days required for first picking from transplanting of seedling was counted, and the average was worked out. The interval between 2 pickings was to be 6 days. The length of fruit cluster was measured from pedicel end to tip of fruit cluster by selecting 10 clusters randomly from each observational plant and later on the average was worked out. The weight of 10 randomly selected fresh fruit clusters were recorded, and an average weight of cluster was worked out. The number of fruits in a cluster was counted for the 10 randomly selected clusters and averaged. The yield data were recorded at each picking from the selected observational 5 plants, and the average was calculated. The total yield per plot was recorded and then multiplied it by hectare factor.

\section{RESULTS AND DISCUSSION}

Growth parameters

Plant height: The plant height was significantly influenced by different shading intensities (Table 1). The significantly maximum mean plant height was ob- served in 75 per cent shading intensity at 30, 60, 90 and 120 days after transplanting (DAT) followed by 50 per cent shading intensity and lowest plant height was observed in open condition. The plant height was influenced by different genotypes during the growth of cherry tomato. The maximum plant height 30 DAT was observed in KSP $-113(60.95 \mathrm{~cm})$ which was at par with EC-128021 while lowest in EC-123021. The significantly maximum plant height 60 DAT was recorded in KSP-113 followed by EC-128021. The lowest plant height 60 DAT was noticed in EC-123021 which was at par with EC-539. The significantly maximum plant height 90 DAT was recorded in KSP-113 followed by EC-128021 while the minimum plant height was noticed in EC-123021. The significantly maximum plant height 120 DAT was observed in KSP-113 followed by EC-128021 while lowest plant height was observed in EC-123021 which was at par with EC-539. The interaction effect between shading intensities and genotypes on the height of plant was found to be significant at 30, 60, 90 and 120 DAT. Among the different shading intensities, maximum plant height was observed by genotype KSP-113 in 75\% shading intensity where as the minimum plant height 30 DAT was recorded by EC-128021, 60 and 90 DAT was recorded by EC-123021, and 120 DAT was observed by EC128021. This may be attributed to profuse vegetative growth due to higher availability of absorbed Photosynthetically Active Radiation (PAR) under $75 \%$ shading intensities and enhanced photosynthesis as well as respiration due to favorable micro-climatic conditions in shade net house. The enhancement in the growth and development under shade net house is by increasing the rate of plant response to diffused sunlight inside the shade net by way of photosynthesis, and respiration resulting in longer inter nodal length and increase in the growth variables in terms of plant height. Similar results were reported by Nangare et al. (2015) in tomatoes grown under green shade net, Khattak et al. (2007) in exotic tomato lines and Elad et al. (2007), Vethamoni and Natarajan (2008) in pepper. The Rajasekar et al. (2013) reported that growing of tomato, brinjal, chilli, cucumber, radish, amaranthus and coriander under shade house conditions would be more profitable irrespective of the seasons.

Yield and yield contributing parameters: The days to $50 \%$ flowering was influenced by different shading intensities. The minimum days to $50 \%$ flowering were observed in 35 per cent shading intensity (45 DAT) which was at par with the open condition and maximum days to $50 \%$ flowering were observed in $75 \%$ shading intensity. The days to $50 \%$ flowering was significantly influenced by different genotypes (Table 2). The significantly minimum days to $50 \%$ flowering were observed in KSP-113 followed by genotype EC128021 which was at par with EC- 539 and maximum days to $50 \%$ flowering was observed in EC-123021. 
M. B. Argade et al. / J. Appl. \& Nat. Sci. 10(1): 352 - 357 (2018)

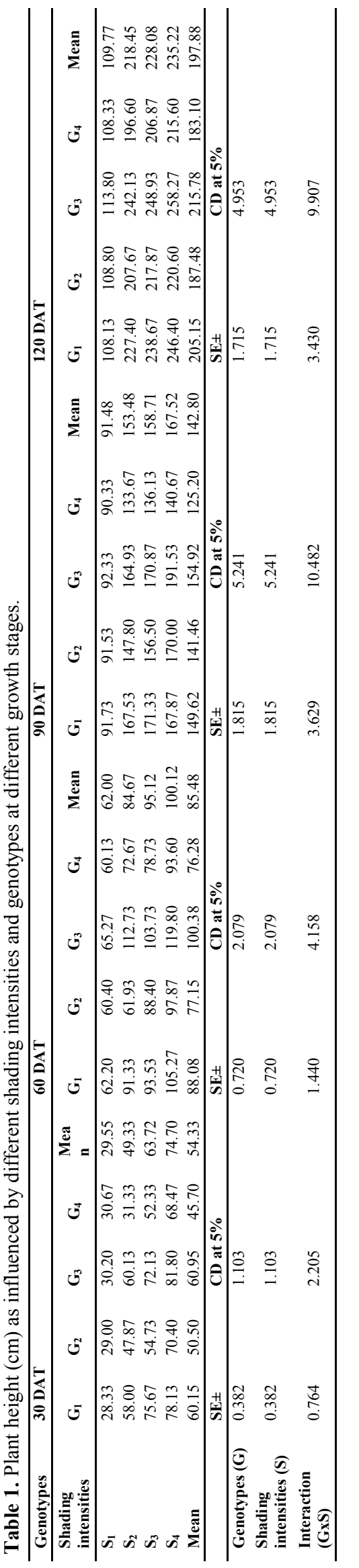

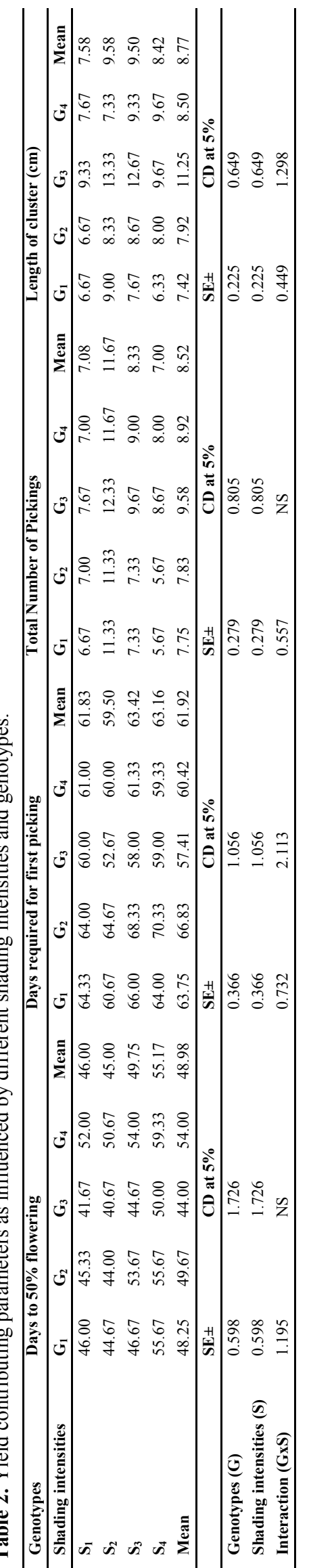

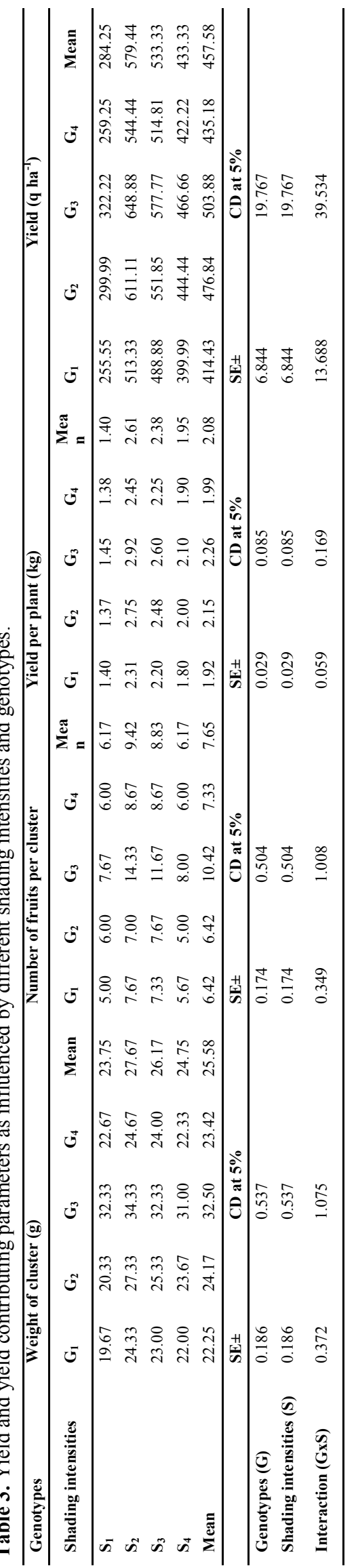


The interaction effect between shading intensities and genotypes on $50 \%$ flowering of the plant was found to be non-significant. Among the different shading intensities minimum days to $50 \%$ flowering was observed by genotype KSP-113 in 35\% shading intensity whereas, the genotype KSP -113 recorded minimum days to $50 \%$ flowering in $75 \%, 50 \%$ shading intensity and open condition. The maximum days to $50 \%$ flowering was observed in $75 \%$ shading intensity by genotype EC-123021. The flowering is affected by the changes in micro-climate under different shading intensities and optimum light and temperature. The vegetative period in tomato increased with decreasing light intensity because the rate of leaf production before the first inflorescence decreased with reduction in light intensity. The similar results were reported by Singh et al. (2013). Runkle and Heins (2001) reported that far red (FR) - deficient environments effectively retard stem extension in many herbaceous plants, they can delay flower initiation in some long day plants.

The days required to first picking were significantly influenced by different shading intensities (Table 2). The significantly minimum days required for first picking were observed in 35 per cent shading intensity (59.50 DAT) followed by an open condition and maximum days required for first picking were observed in $50 \%$ shading intensity which was at par with $75 \%$ shading intensity. The days required to first picking were significantly influenced by different genotypes. The significantly minimum days required for first picking were observed in KSP-113 followed by genotype EC- 123021 and maximum days required for first picking were observed in EC-539. This might be due to the maximum photosynthetic surface for the synthesis of assimilates is available in KSP-113 due to profuse vegetative growth which requires more number of pickings. The interaction effect between shading intensities and genotype on days required for first picking of cherry tomato was found to be significant. Among the different shading intensities, minimum days to first picking were recorded by genotype KSP-113 in 35\% shading intensity, where as the genotype KSP -113 recorded minimum days to first picking in 50\%, 75\% shading intensities and open condition. The maximum days to first picking were observed in $75 \%$ shading intensity by genotype EC-539. This might be due to enhanced photosynthesis due to favorable microclimatic conditions in shade net house which triggered early picking.

The total number of pickings was significantly influenced by different shading intensities (Table 2). The significantly maximum number of pickings were observed in 35 per cent shading intensity (11.67 pickings) followed by $50 \%$ shading, and a minimum number of picking were observed in $75 \%$ shading intensity which was at par with the open condition. The total number of pickings was significantly influenced by different genotypes. The significantly maximum number of pickings were observed by KSP-113 followed by genotype EC- 123021 and a minimum number of picking were observed in EC-128021which was at par with EC-539. The interaction effects between shading intensities and genotypes on a total number of pickings of cherry tomato were found to be non-significant. Nanagare et al. (2015) by growing tomatoes under green shade nets and Dieleman and Heuvelink (1992) in tomato observed that vegetative period increased with decreasing light intensity. They observed that fruit initiation was favoured by full sunlight, while a number of flowers and fruits were generally higher under shade ultimately the number of pickings was maximum in the shade house.

The length of the cluster was influenced by different shading intensities (Table 2). The maximum length of the cluster was observed in 35 per cent shading intensity which was at par with $50 \%$ shading followed by $75 \%$ shading intensity, and minimum length of the cluster was observed in open condition. The length of the cluster was significantly influenced by different genotypes. The significantly maximum length of the cluster was observed in KSP-113 followed by genotype EC- 123021 which was at par with the EC-539 and minimum length of the cluster was observed in EC128021. The interaction effect between shade net intensities and genotypes on the length of a cluster of cherry tomato was found to be significant. Among the different shading intensities, the maximum length of the cluster was observed by genotype KSP-113 in 35\%, shading intensity where as the minimum length of the cluster was observed in $75 \%$ shading intensity by genotype EC-128021. The tomato plants are grown in shade house, or polyhouse condition recorded maximum length of the cluster. These results are in conformity with the results reported by Kang and Sindhu (2005) and Parvej et al. (2010) in tomato.

The weight of cluster was significantly influenced by different shading intensities (Table 3). The significantly maximum weight of cluster was observed in 35 per cent shading intensity followed by $50 \%$ shading, and a minimum weight of cluster was observed in open condition. The weight of cluster was significantly influenced by different genotypes. The significantly maximum weight of cluster was observed in KSP-113 followed by genotype EC- 539 and minimum weight of cluster was observed in EC-128021. The interaction effect between shade net intensities and genotypes on the weight of cluster of cherry tomato was found to be significant. Among the different shading intensities, maximum weight of cluster was observed by genotype KSP-113 in 35\% shading intensity where as a minimum weight of cluster was observed in open condition by genotype EC-128021. The tomato plants are grown in shade house or polyhouse condition recorded the maximum weight of cluster. These results are in ac- 
cordance with the results reported by Kang and Sindhu (2005) and Parvej et al. (2010).

The number of fruits per cluster was significantly influenced by different shading intensities (Table 3 ). The significantly maximum number of fruits per cluster was observed in 35 per cent shading intensity followed by $50 \%$ shading intensity, and a minimum number of fruits per cluster were observed in open condition and $75 \%$ shading intensity. The number of fruits per cluster were significantly influenced by different genotypes. The significantly maximum number of fruits per cluster was observed in KSP-113 followed by genotype EC - 123021 and minimum number of fruits per cluster were observed in EC-128021 and EC-539. The interaction effects between shade net intensities and genotypes on a number of fruits per cluster of cherry tomato were found to be significant. Among the different shading intensities, a maximum number of fruits per cluster was observed by genotype KSP-113 in $35 \%$ shading intensity whereas the minimum number of fruits per cluster was observed in 75\% shading intensity by genotype EC-539 and open condition by genotype EC-128031. The tomato plants are grown in shade house, or polyhouse condition has a higher number of fruits. The similar results were reported by Kang and Sindhu (2005) and Parvej et al. (2010) in tomato.

The yield per plantwas significantly influenced by different shading intensities (Table 3). The significantly maximum yield per plant was observed in 35 per cent shading intensity $(2.61 \mathrm{~kg})$ followed by $50 \%$ shading and minimum yield per plant was observed in open conditions. The yield per plant was significantly influenced by different genotypes. The significantly maximum yield per plant was observed in KSP-113 followed by genotype EC- 539 and minimum yield per plant were observed in EC-128021 which was at par with EC-123021. The interaction effect between shade net intensities and genotypes on yield per plant of cherry tomato was found to be significant. Among the different shading intensities, maximum yield per plant was observed by genotype KSP-113 in 35\% shading intensity where as minimum yield per plant was observed in open condition by genotype EC-123021. Zoran et al. (2012) observed that yield per plant increased with shading levels up to $40 \%$ shading and then decreased with increasing shading level to $50 \%$ in tomato. The greater fruit yield produced from shaded plants might be due to high temperature during summer leading in to shading of flowers and reduced fruit set.

The yield per hectare was significantly influenced by different shading intensities (Table 3). The significantly maximum yield per hectare was observed in 35 per cent shading intensity (579.44 q) followed by $50 \%$ shading and minimum yield per hectare was observed in open conditions. The yield per hectare was significantly influenced by different genotypes. The signifi- cantly maximum yield per hectare was observed in KSP-113 followed by genotype EC- 539 and minimum yield per hectare was observed in EC-128021. The interaction effect between shade net intensities and genotypes on yield per hectare of cherry tomato was found to be significant. Among the different shading intensities, maximum yield per hectare was observed by genotype KSP-113 in 35\% shading intensity where as minimum yield per hectare was observed in open conditions by genotype EC-128021. It has been observed that under $35 \%$ shade net formation of photosynthates and their partitioning and distribution for the final sink were higher as compared to 50 and $75 \%$ green shade nets (Nangare et al., 2015). These results are in accordance with findings of Priya et al. (2002). Tomato, eggplant, capsicum, radish, amaranthus and coriander had higher yield under shade net house due to light compensation for higher photosynthesis. Significantly the lowest yield was observed in open conditions. The similar results were obtained in cauliflower by Swagatika et al. (2006), Vethamoni and Natarajan (2008) in sweet pepper and Haque et al. (2009) in bottle gourd.

\section{Conclusion}

The shade net protects the plants from frost and cold waves during winter and from solar injury due to high intensity solar radiation during summer. This positively influenced the morpho-phenological and physiological events of tomato plants. It is concluded that the better growth, development and yield of tomato were achieved under shade net due to optimum temperature and humidity. Among the different genotypes studied genotype KSP-113 recorded highest yield (503.88 q ha $\left.{ }^{-1}\right)$ under 35 per cent shading intensity $\left(579.44 \mathrm{q} \mathrm{ha}^{-1}\right)$. Hence growing of KSP-113 genotype of cherry tomato under 35 per cent shading intensity was found to be most suitable for achieving higher yield during the summer season.

\section{ACKNOWLEDGEMENTS}

Tomato Improvement Project, Mahatma Phule Krishi Vidyapeeth, Rahuri and The Kalash Seeds Pvt. Ltd., Jalna, Maharashtra is acknowledged for supplying seeds of different genotypes required for the study.

\section{REFERENCES}

Dieleman, J. A. and Heuvelink, E. (1992). Factors affecting the number of leave preceding the first inflorescence in the tomato. J. Hort. Sci., 67: 1-10

Elad, Y., Messika, Y., Brand, M., David, D.R. and Sztejnberg, A. (2007). Effect of coloured nets on pepper powdery mildew. Phytoparasitica, 35(3):285-299.

Haque, M. M., Hasanuzzaman, $\mathrm{M}$ and Rahman, M. L. (2009). Effect of light intensity on morpho- physiology and yield of bottle gourd (Lagenaria vulgaris). Acad. J. Plant Sci., 2(3) 158-161. 
Kang, B. S. and Sindhu, B. S. (2005). Studies on growing off -season tomato nursery under polyhouse. Annals of Agril. Bio. Res., 10(1): 53-56.

Khattak, A. M., Abdul Salam, A. and Nawab, K. (2007). Response of exotic tomato lines to different light intensities. Sarhad J. Agric., 23(4): 927-932.

Mantur, S. M., Biradar, M.S., Patil A. A. and Mannikeri, I. M. (2014). Effect of spacing on cherry tomato varieties grown under shade house. Karnataka J. Agric. Sci., 27 (2): 199-201.

Nangare, D. D., Singh, J., Meena, V. S., Bhushan, B. and Bhatnagar, P. R. (2015). Effect of green shade nets on yield and quality of tomato (Lycopersicon esculentum Mill) in semi-arid region of Punjab. Asian J. of Advances in Basic and Applied Sciences. 1 (1):1-8.

Parvej, M. R., Khan, M.A.H. and Awal, M.A. (2010). Phenological development and production potentials of tomato under polyhouse climate. J. agric. Sci., $5(1): 19-31$.

Priya, W., Vijayakumar, M., Veeragavathatham, D., Jeyakumar, P and Chezian, N. (2002). Effect of season and growth environment on paprika (Capsicum annum var. lonum) growth and yield. South Indian Hort., 50 (4-6):
463-471.

Rajasekar, M., Arumugam, T. and Ramehkumar, S. (2013). Influence of weather growing environment on vegetable growth and yield. J. Hort. and forestry, 5(10): 160-167.

Runkle, E. S. and Heins, R. D. (2001). Photo control of flowering and extension growth in the long day plant pansy, J. Hort. Sci., 128(4): 479-484.

Singh, V.A. K, Bhatia, D, Duhan, D, Majoka, M and Singh, A. (2013). Performance of different tomato hybrids under greenhouse conditions. Crop Res. Hisar 46 (1/3): 188-191.

Swagatika, S, Panda, S.C., Sahu, G.S., Mahapatra, P. and Mishra, R. (2006). Effect of shade net on growth and yield of cauliflower. Orissa J. Hort., 34(1): 28-31.

Vethamoni, P. I. and Natarajan, S. (2008). Cultivation of sweet pepper cultivars (Capsicum annuum var. grossum L.) under shade net in tropical plains of Tamil Nadu. Asian J. Hort., 3(2): 372-376.

Zoran, S., Lidija Milenkovic, L., Stanojevic, L., Dragan Cvetkovic, D. and Elazar Fallik. (2012). Effects of the modification of light intensity by color shade nets on yield and quality of tomato fruits. Sci. Hort., 139:90-95. 